\begin{tabular}{|l|l|l|l|l|l|l|}
\hline InterteXto & Uberaba & UFTM & $\begin{array}{l}\text { v. 1 } \\
\text { n. } 2\end{array}$ & p. 147-166 & 2008 - jul. / dez. & ISSN 1981-0601 \\
\hline
\end{tabular}

\title{
A LINGUAGEM ESPACIAL EM LA BÊTE HUMAINE ${ }^{1}$
}

Denis Bertrand ${ }^{2}$

Vasta cenografia do visível, a obra de Zola pode parecer comandada por uma meditação sobre o espaço. De algumas figuras espaciais mestras irradia, em diferentes romances, uma significação que desborda amplamente sua atribuição referencial. É por isso que o estudo particular do universo "visível" nesta obra conduz a uma reflexão mais geral sobre o estatuto semiótico: os vínculos que ele mantém com a ação romanesca, com os sujeitos cuja identidade ele sustenta, com a axiologia e seus suportes modais ${ }^{3}$. A análise de Germinal nos tinha também sugerido uma hipótese no que diz respeito à implicação global da espacialidade. Nós retornaremos a isso. Mas, além de sua eventual legitimidade descritiva para este romance, ela tinha uma aspiração mais profunda: a de revelar um funcionamento geral do discurso espacial que regula diversos níveis de leitura, um nível figurativo e um nível abstrato, assegurando com isso a eficácia particular, em termos de recepção, da escritura romanesca de Zola. Nós nos dedicávamos então na direção de uma certa poética da legibilidade, esforçando-nos por esclarecer alguns de seus princípios fundamentais e descobrindo-os precisamente em torno da espacialidade. Uma pesquisa ligada à descrição de propriedades subjacentes à

\footnotetext{
${ }^{1}$ A tradução deste texto, autorizada pelo autor, foi executada pelo Prof. Geraldo Majela de Morais Santos. profrances@ig.com.br . Este texto foi publicado anteriormente no livro Mimesis et semiosis - littérature et represéntation. HAMON, Philippe et LEDUC-ADINE, Jean Pierre. (org.) Editions Nathan, 1992.

${ }^{2}$ Professor doutor titular de Letras de cursos de pós graduação em lingüística, Denis Bertrand é diretor do Departamento de estudos para as línguas e as culturas do Centro internacional de estudos pedagógicos da cidade de Sèvres na França. Ele publicou L'Espace et le sens Germinal d'Émile Zola, prefaciado por Henri Mitterand e numerosos artigos em revistas de semiótica e de lingüística.

${ }^{3}$ Numerosos trabalhos foram consagrados a esta questão. Ver especificamente em G. Deleuze, "Zola et la fêlure", Logique du sens, Paris, Minuit, 1969 ; Ph. Hamon, Introduction à l'analyse du descriptif,, Paris, Hachette, 1981 ; D. Bertrand, L'espace et le sens, ParisAmsterdam, Hadès-Benjamin, $1985 ; \mathrm{H}$. Mitterand, « Figures de l'espace », Zola. L'histoire et la fiction, Paris, P.U.F., 1990.
} 


\begin{tabular}{|l|l|l|l|l|l|l|}
\hline InterteXto & Uberaba & UFTM & $\begin{array}{l}\text { v. 1 } \\
\text { n. } 2\end{array}$ & p. 147-166 & 2008 - jul. / dez. & ISSN 1981-0601 \\
\hline
\end{tabular}

escritura zolaniana tinha o dever de ser experimentada - verificada e reforçada, ou enfraquecida e invalidada - sobre um corpus mais amplo que o de um só romance. É, portanto, testando esta hipótese que gostaríamos de nos deter aqui examinando alguns dispositivos espaciais da obra La Bête humaine, suscetíveis de fundamentar o que se pode chamar uma "linguagem espacial".

Este estudo se inscreve dentro de um dos domínios de exploração da semiótica literária e diz respeito ao estatuto da figuratividade: sua posição como conceito operatório na teoria da linguagem e particularmente a distinção entre dois níveis, o de uma "figuratividade de superfície" que coloca por assim dizer "sob os olhos" os objetos do mundo natural e os oferece para serem vistos pelo leitor como se ela o convidasse a se situar entre eles, e o de uma "figuratividade profunda" que rege uma dimensão mais abstrata do discurso, de ordem interpretativa e hermenêutica, impondo seus efeitos de verdade e assegurando sua credibilidade. A relação entre esses dois níveis produz o que chamamos às vezes "raciocínio figurativo": haveria assim em Zola uma forma de "raciocínio espacial"?

Tentaremos sugeri-lo primeiramente através de uma confrontação de "estações ferroviárias": uma de Zola - a célebre descrição inicial da estação Saint - Lazare na obra La Bête humaine - e a outra de Claude Simon extraída da obra L'Acacia. Estas duas descrições de um mesmo lugar, que um século separa, exprimem duas "poéticas da percepção" eminentemente sensíveis: a primeira nos parece voltada para sua avalização cognitiva, abrindo-se conseqüentemente sobre a simbolização, isto é sobre a possibilidade de dispor os conteúdos espaciais como os significantes de um outro discurso; a outra, ao contrário, volta-se para a origem da percepção, aplicada ao processo de sua ascensão, entravando por essa razão o desenvolvimento cognitivo, ou engajando em todo caso uma aventura do conhecimento de qualquer outra ordem.

A análise contrastiva, que faz emergir as características da figuratividade espacial em La Bête humaine, tornará então possível um alargamento maior de 


\begin{tabular}{|l|l|l|l|l|l|l|}
\hline InterteXto & Uberaba & UFTM & $\begin{array}{l}\text { v. } 1 \\
\text { n. } 2\end{array}$ & p. 147-166 & 2008 - jul. / dez. & ISSN 1981-0601 \\
\hline
\end{tabular}

seu alcance: parece-nos, com efeito, que uma "gramática" elementar do espaço, que se baseia sobre as figuras da junção, da rede, do percurso, da suspensão do espaço juntivo, etc., assegura ao nível da espacialidade profunda ao qual ela pertence, a estreita conexão entre os dois "romances" que compõem La Bête humaine, o figurativo, da estrada de ferro, e o epistêmico, do inquérito policial, cuja difícil convergência constitui, como sabemos, um dos fatos mais notáveis na gênese do romance. Sobre o pano de fundo de uma linguagem espacial comum estabelecer-se-ia o vínculo especular entre as formações do conhecimento sensível, que rege o figurativo $e$ as do conhecimento inteligível, que rege os valores epistêmicos da certeza e da "íntima convicção" de um julgador. Este vínculo, que restabelece às escondidas a dualidade temática, garantiria pela mesma ação a unidade efetiva do texto.

\section{A figuratividade em semiótica}

A análise semiótica do discurso se baseia, como se sabe, no postulado hjelmsleviano da "autonomia essencial da língua" e das organizações significantes. Ou seja, ela não autoriza um retorno imediato e desenvolto à referência ou à representação do "real". O Dictionnaire raisonné de la théorie du langage 4 (Dicionário lógico da teoria da linguagem) considera de forma muito clara que o conceito de "referente" não tem pertinência dentro do quadro teórico ao qual ele pertence. Na realidade, a exclusão do referente, ou de preferência sua problematização, cede lugar a uma abordagem fenomenológica das relações entre o discurso e o mundo. Sua relação não é compreendida como uma "designação", mas como uma correlação entre duas semióticas. O mundo natural, visto que sua forma é dada de imediato pela percepção, já deve ser considerado em si como uma linguagem biplana, que comporta um plano da expressão e um plano do conteúdo: ele é construído -

\footnotetext{
${ }^{4}$ A.-J. Greimas, J. Courtés, Paris, Hachette, 1979.
} 


\begin{tabular}{|l|l|l|l|l|l|l|}
\hline InterteXto & Uberaba & UFTM & $\begin{array}{l}\text { v. } 1 \\
\text { n. } 2\end{array}$ & p. 147-166 & 2008 - jul. / dez. & ISSN 1981-0601 \\
\hline
\end{tabular}

lido, interpretado - como uma semiótica. Como o escreve Michel de Certeau em um comentário do Visible et l'invisible (Visível e o invisível) de MerleauPonty: "Ver já é um ato de linguagem. Este ato faz das coisas vistas a enunciação da invisível estrutura que as une5", fazendo de certa forma eco a uma reflexão do próprio Merleau-Ponty a propósito da experiência da percepção: "esta experiência nos coloca diante do momento em que se constituem para nós as coisas [...]; ela nos proporciona um logos no seu estado nascente." O mundo do senso comum se desdobra então como uma linguagem figurativa articulada em "propriedades sensíveis" inseparáveis de "propriedades discursivas". Estas podem ser formuladas nos termos de uma organização semio-narrativa que serve de base à percepção de cada figura do mundo natural: uma micro-sintaxe que regula as interações entre os sujeitos que percebem e os objetos percebidos a assume, por assim dizer, simultaneamente. A percepção "se lembra e antecipa, ela vai sempre para frente e retroage", ela é expectativa e previsão, ela integra a "salvaguarda" e a "apropriação", de acordo com os termos de Maurice Pradines6.

São estas mesmas figuras, desenvolvidas no seio de percursos narrativos virtuais ou realizados, que constituem a dimensão semântica dos discursos que denominamos "figurativa". Graças a elas o mundo "nos fala". A figuratividade se define então como todo conteúdo de um sistema de representação, verbal, visual ou outro, que se acha correlato a uma figura significante do mundo percebido quando de sua assunção dentro do discurso. As formas de adequação, instáveis e culturalmente trabalhadas pelo uso, entre estas duas semióticas - a do mundo natural e a das manifestações discursivas das linguagens naturais - , remetem a uma problemática que ultrapassa nosso propósito. Mas nós podemos conservar delas uma posição

\footnotetext{
${ }^{5}$ M. de Certeau, "La folie de la vision", in "Maurice Merleau-Ponty", Esprit, 66, Paris, 1982, p. 97.

${ }^{6}$ M. Pradines, La Fonction perceptive, Paris, Denoël/Gonthier, 1981.
} 


\begin{tabular}{|l|l|l|l|l|l|l|}
\hline InterteXto & Uberaba & UFTM & $\begin{array}{l}\text { v. } 1 \\
\text { n. } 2\end{array}$ & p. 147-166 & 2008 - jul. / dez. & ISSN 1981-0601 \\
\hline
\end{tabular}

que P. Fabbri resume em uma expressão: "O real não se relata, profere-se7." Esse problema interessa diretamente ao romance que chamamos "realista" e que o é apenas em virtude de uma certa poética da escritura: a realidade tornase "legível" como um efeito específico do discurso realizado. Este a constrói como um ponto de chegada de seus procedimentos de referencialização: nesta perspectiva, a descrição de tais procedimentos constitui o objetivo efetivo de nossas análises.

\section{O figurativo profundo}

É assumindo esta concepção geral que nós fomos levados, há alguns anos, a nos questionar sobre as expansões semânticas da espacialidade em Germinal e conduzidos a reconhecer a existência de uma verdadeira "linguagem espacial" característica da arquitetura zolaniana do discurso8. A espacialidade regia somente uma ordem de representação figurativa do mundo sensível, a topografia, o cenário e os movimentos dos personagens, ou então a mesma não formava ao mesmo tempo uma "topologia" mais abstrata, responsável por outras funções textuais?

Cobrindo de uma extremidade a outra o universo romanesco de Germinal, a isotopia espacial se apresenta como um sistema, ao mesmo tempo paradigmático (a oposição entre "a planície e a mina subterrânea, a superfície e o fundo) e sintagmático (pelas transformações sucessivas das relações antagônicas entre a superfície e o fundo). A busca dos mineiros aparece nesta perspectiva como a de um lugar de residência para seus valores: nada de axiologia sem território. Excluídos da superfície, eles tentam conquistá-la quando da greve geral; ao término desta, eles retornam ao fundo. Mas o desabamento do poço da mina, levando a planície para dentro do abismo,

\footnotetext{
${ }^{7} \mathrm{P}$. Fabbri, Introduction à l'édition italienne de Sémiotique. Dictionnaire raisonné de la théorie du langage, trad. fr., Nouveaux Actes sémiotiques, Limoges, PULIM, 1992.

${ }^{8}$ L'Espace et le sens, op. cit.
} 


\begin{tabular}{|l|l|l|l|l|l|l|}
\hline InterteXto & Uberaba & UFTM & $\begin{array}{l}\text { v. 1 } \\
\text { n. } 2\end{array}$ & p. 147-166 & 2008 - jul. / dez. & ISSN 1981-0601 \\
\hline
\end{tabular}

anula por sua vez os valores que lá residiam. Os pólos excluindo-se assim mutuamente, a solução se acha na figura final da germinação: é ela quem, ao mesmo tempo subterrânea e aérea, abriga o nascimento de uma nova axiologia.

Porém, esse sistema de conexões espaciais, reduzido às suas figuras mais abstratas, nos pareceu manter juntos o dispositivo figurativo do romance e seu dispositivo interpretativo - ou mesmo anagógico, na medida em que se desenha nele uma visão última do senso. Os dois discursos, concreto e abstrato, apoiando sobre uma mesma estruturação da espacialidade, se referencializam um ao outro; em outros termos, o sistema espacial assegura a coesão recíproca de um discurso de representação dos acontecimentos e de um discurso "hermenêutico" que dizem respeito ao progresso social e político da humanidade. Afastando-nos desde logo da referência ao mundo exterior ao texto, o da natureza e da história, nós fomos levados a nos questionar sobre os processos mais ocultos da referencialização interna, percebendo neles uma "chave" possível da credibilidade e da eficácia simbólica do discurso romanesco, em suma do sucesso de Germinal. Os modos de funcionamento das realidades perceptivas exibidas no texto se achavam de certa forma garantidos através de um projeto filosófico de inteligibilidade cuja elaboração reproduzia as estruturas exatamente da mesma maneira; e inversamente, as finalizações mais ou menos arriscadas do discurso teórico tinham seu apoio natural e encontravam sua confirmação epistêmica numa organização do conhecimento sensível que lhes remetia seu esquematismo espacial. 0 inteligível tornava-se tanto mais convincente quanto fosse sustentado pelo sensível, e o sensível tanto mais "real" quanto ele achasse confirmado pelo inteligível. Esta significação, simultaneamente mostrada e demonstrada, repousava sobre um duplo uso de um mesmo esquema espacial: o significado do discurso figurativo articulava categorias e relações que operavam como significantes para produzir o discurso teleológico e abstrato. Através desse laço particular tramado na escritura desenhava-se pela mesma ação uma certa 


\begin{tabular}{|l|l|l|l|l|l|l|}
\hline InterteXto & Uberaba & UFTM & $\begin{array}{l}\text { v. } 1 \\
\text { n. } 2\end{array}$ & p. 147-166 & 2008 - jul. / dez. & ISSN 1981-0601 \\
\hline
\end{tabular}

concepção do saber verdadeiro e perfilava-se a "epistemologia" especifica de um sujeito cognitivo. Este não era outro senão o próprio autor, Zola, definido indiretamente e por assim dizer do interior, pelas configurações, os ordenamentos e as manipulações do que se tinha tornado verdadeiramente uma "linguagem espacial". Nisso o espírito zolaniano unia o mundo dos "espíritos pré-científicos", aqueles que são entusiasmados pela fusão entre o concreto e o abstrato e que, segundo G. Bachelard, são "tão mais seguros de sua abstração quanto esta abstração é mais claramente representada por uma intuição sensível9". Tendo conseguido, por uma conduta semântica, a hipótese desta "identificação" cognitiva, parecia-nos necessário verificá-la, dentro de um senso ou de outro, testando-a em outros textos do mesmo autor. O caso de La Bête humaine nos pareceu exemplar sob esta perspectiva: embora central aí também, o dispositivo espacial se organiza em torno de outra figura qualquer; a "linha" se substitui pelo "poço", a horizontalidade pela verticalidade. As categorias que regem um processo eventualmente similar darão destaque então a uma ordem figurativa necessariamente diferente.

\section{Visões das estações ferroviárias}

Antes de considerar este novo dispositivo em seu conjunto, é necessário pesquisar, através de uma micro-análise, o que é susceptível de fundamentar dele seus caracteres próprios. É necessário então que nós tentemos remontar à fonte de uma certa poética da percepção espacial. Como o discurso zolaniano (re)constrói a percepção? Quais relações ele estabelece entre a percepção e o sujeito do saber? Como o texto romanesco fixa uma certa esquematização cultural da percepção: um certo uso da visibilidade?

Para fazer aparecer de forma suficientemente viva alguns elementos de resposta a essas questões, nós optamos então por confrontar duas estações

${ }^{9}$ G. Bachelard, La formation de l'esprit scientifique. Contribution à la psychanalyse de la connaissance objective, Paris, Vrin, 1975, p. 8. 


\begin{tabular}{|l|l|l|l|l|l|l|}
\hline InterteXto & Uberaba & UFTM & $\begin{array}{l}\text { v. 1 } \\
\text { n. } 2\end{array}$ & p. 147-166 & 2008 - jul. / dez. & ISSN 1981-0601 \\
\hline
\end{tabular}

ferroviárias, "vistas" por Émile Zola e Claude Simon. Tomando inicialmente a visão para nos levar ao que o texto nos diz da espacialidade, nós consideramos que a contribuição da literatura é de certo modo decisiva, e que ela é, por um lado, constitutiva da visão em si mesma.: "A literatura traça na língua o insensato da visão" (M. de Certeau). Trata-se, portanto de procurar compreender o que o discurso nos diz da visão, de exprimir com exatidão como ele regula a partir dela uma certa ordem cultural e atesta uma utilização, como enfim, desenvolvendo a partir dela o imperceptível da percepção, ele a faz acontecer como significação. O trabalho textual de Claude Simon, que contrasta vigorosamente com o de Zola, nos parece importante a este respeito: ele impõe uma espécie de golpe de força nas formas sedimentadas pelo uso, ao se fazer desligar das figuras sensíveis que a tradição discursiva da percepção apresentava, isoláveis e unificadas, como "evidentemente" nomeáveis. Ele nos faz ir à gênese e ao advento da percepção, enquanto que a escrita zolaniana parece, ao contrário, fazer par com ela, lhe dar o aval e prolongar as conseqüências além do próprio evento perceptivo. Encontramonos então na presença de duas esquematizações figurativas distintas da percepção. Porém em Zola, é o desenvolvimento deste modelo espacial que nos parece responsável pela unificação dos dois discursos, o das estradas de ferro e o das estradas do saber, em La Bête humaine.

Sob a coberta das grandes linhas férreas, a chegada de um trem de Mantes tinha deixado as plataformas de embarque animadas; e ele acompanhou com os olhos a máquina de manobra, uma pequena máquinatênder, de três rodas baixas unidas duas a duas, que começava o desengate e a separação dos vagões do trem, alerta, cuidadosa, indo de um lado para outro, comprimindo os vagões sobre os trilhos no pátio de recolhimento. Outra máquina, esta possante, uma máquina de trem expresso, com duas grandes rodas devoradoras, estacionava sozinha, soltava pela sua chaminé uma densa fumaça negra, que subia direito, muito lentamente no ar calmo. Mas toda sua atenção foi tomada pelo trem das três e vinte e cinco, com destino a Caen, já 


\begin{tabular}{|l|l|l|l|l|l|l|}
\hline InterteXto & Uberaba & UFTM & $\begin{array}{l}\text { v. } 1 \\
\text { n. } 2\end{array}$ & p. 147-166 & 2008 - jul. / dez. & ISSN 1981-0601 \\
\hline
\end{tabular}

ocupado com seus passageiros, e que esperava a sua máquina. Esta, ele não percebia parada para além da Ponte da Europa; ouvia-a apenas pedir passagem, com ligeiros apitos apressados, como uma pessoa que a impaciência domina. Uma ordem foi gritada, ela respondeu com um toque breve que havia compreendido. Depois, antes de pôr-se em movimento, houve um silêncio, os purgadores foram abertos, o vapor silvou ao nível do chão, num jato ensurdecedor. E ele viu, então, transbordar da ponte aquela névoa branca que se multiplicava em profusão, aos turbilhões como um floco de neve, que voava bruscamente por entre as estruturas de ferro. Toda uma porção do espaço estava esbranquiçada, ao passo que as fumaças acrescidas da outra máquina ampliavam o véu negro delas. Atrás, sons prolongados de corneta, gritos de comando, sacudidelas de placas giratórias. Uma grande abertura se produziu, ele distinguiu, ao fundo, um trem de Versalhes e um trem de Auteuil, um subindo, outro descendo, que se cruzavam. (Émile Zola. La Bête humaine (1890), ch. 1, Gallimard, La Pléiade, t. IV, p. 998) 


\begin{tabular}{|l|l|l|l|l|l|l|}
\hline InterteXto & Uberaba & UFTM & $\begin{array}{l}\text { v. 1 } \\
\text { n. } 2\end{array}$ & p. 147-166 & 2008 - jul. / dez. & ISSN 1981-0601 \\
\hline
\end{tabular}

Ao mesmo tempo aérea e monumental, aproximando-se em marcha lenta, como que carregada sobre uma nuvem, os jatos de vapor fundente entre as bielas forradas de um óleo amarelado, sacudindo o solo sob sua massa, puxando atrás dela uma seqüência de vagões de um modelo antigo exumados dos depósitos onde sem dúvida os conservavam já prevendo este dia (fabricados em madeira, pintados de uma cor marrom descascada e providos de uma passagem em cada uma de suas extremidades), a locomotiva penetrou com um surdo estrondo sob os vitrais da estação onde, sobre a plataforma de embarque se espremia uma multidão compacta cuja primeira fileira recuou um passo para trás à sua aproximação, não tanto por temor de ser escaldada pelo vapor ou de escorregar sob as rodas, mas por uma espécie de instintivo horror, de intuitivo instinto de repulsa que a obrigava a conservar o maior tempo possível entre ela e a parede vertical dos vagões desfilando cada vez mais lentamente, um ilusório e último intervalo de vazio, como um fosso, um estreito cânion ou de preferência uma invisível muralha, uma invisível barreira além da qual, uma vez transposta, estaria selado algo de irremediável definitivo e terrível. (Claude Simon, L 'Acacia, VI, Paris, Éd. de Minuit, 1989, p. 153-154)

O ponto de vista que nós adotamos diz respeito essencialmente ao papel da dimensão cognitiva na construção perceptiva das duas estações: no primeiro caso, a percepção está inteiramente situada sob a égide do /saber/ que a rege; no segundo, ela é tomada na sua textura, voltada para o /crer/ que a fundamenta e que submete aos seus entrelaçamentos a progressiva formação do /saber/. Trata-se de uma percepção irrefletida, sujeita ao movimento de uma "fé perceptiva" (Merleau-Ponty): é precisamente sobre este espaço de irreflexão que a escritura marca uma parada, tornando-a por assim dizer "visível" em troca de uma proximidade atenta que integra em seu enunciado as manifestações cognitivas dentre outras.

Pelo lado de Zola, a construção parece se fazer com o aval de uma inteligibilidade que é dada em primeiro lugar. Como o escreve Bernard Noël, "o olho, quem não confia nele? Nós cremos no que nós vemos10". Esta construção busca todo seu apoio sobre a figura de um sujeito observador, "ele",

${ }^{10}$ B. Noël, Journal du regard, Paris, P.O.L., 1988 p. 14. 


\begin{tabular}{|l|l|l|l|l|l|l|}
\hline InterteXto & Uberaba & UFTM & $\begin{array}{l}\text { v. } 1 \\
\text { n. } 2\end{array}$ & p. 147-166 & 2008 - jul. / dez. & ISSN 1981-0601 \\
\hline
\end{tabular}

fonte do saber, verdadeira sentinela do conhecimento, que determina, controla e ordena e que enfim, sobre o fundo inalterável desta confiança, torna possível a expansão semântica das imagens percebidas: ele autoriza, desta maneira, a expansão simbólica do figurativo, sua mudança de substância, sua hipóstase.

Pelo lado de Claude Simon, observa-se ao contrário, senão um apagamento, pelo menos um enfraquecimento do sujeito. Mesmo que se tratasse do observador pressuposto pela enunciação ou então do sujeito do enunciado (a locomotiva), a figura do sujeito está literalmente afogada na processualidade do percurso perceptivo que forma o cerne da descrição. Esta se desdobra, por aproximações e contigüidades sucessivas, fora-sujeito e foraobjeto, por assim dizer no entre os dois. O saber-fazer, sob forma de avaliações, de hipóteses e de previsões, entremeia-se com o sensível. Suas emergências estão ligadas e submetidas às do visível, ele se torna tão sensível quanto o sensível.

\section{Visão e inteligibilidade}

Em Zola, um duplo sistema, semântico e enunciativo, estabelece a arquitetura: uma seqüência de localizações ("Sob a coberta", "parada para além da Ponte da Europa", "transbordar da ponte", “atrás", "ao fundo") determina, entre cada estágio, numerosas isotopias espaciais que têm a função de moldura; a coberta não está lá para ser vista, mas para delimitar o espaço cognitivo do quadro. Um conjunto de predicados visuais, em seguida, circunscreve as operações do observador ("ele acompanhou com os olhos", "toda sua atenção foi tomada", "ele viu, então, transbordar" e finalmente "ele distinguiu"): ele é a peça mestra de uma cena que ele articula e sustenta pelos diferentes regimes do saber. O que se situa fora do seu campo visual ("ele não percebia") não é apreendido em virtude de uma síntese visual "de transição" (Merleau-Ponty), mas por uma síntese intelectual: o que ele não vê não está colocado como "visível de outro lugar" e nem está presente e iminente sob 


\begin{tabular}{|l|l|l|l|l|l|l|}
\hline InterteXto & Uberaba & UFTM & $\begin{array}{l}\text { v. 1 } \\
\text { n. } 2\end{array}$ & p. 147-166 & 2008 - jul. / dez. & ISSN 1981-0601 \\
\hline
\end{tabular}

outras perspectivas, mas impõe-se simplesmente pela espera do trem; a locomotiva invisível é uma causa esperada, ela deve aparecer.

O percurso se apresenta então como uma pequena narrativa do mundo inteligível. O observador não se contenta em ver ou ouvir, ele lê o sentido do que ele percebe. Ver e compreender tornaram-se indissociáveis. Ele "vê" as relações, os acoplamentos, a seqüência interrompida das conjunções e das disjunções, as expectativas percebidas como causas, os olhares últimos dos deslocamentos, em suma, toda esta micro-narratividade da qual as máquinas são os atores. O saber segundo da inteligibilidade englobou o movimento ou a imobilidade dos trens, o evidente ou o não-evidente das figuras, o nítido ou o difuso das imagens que compõem o quadro. Destacada da percepção que a fundamenta inicialmente, a figuratividade está então pronta para outras funções: ela se abre sobre a possibilidade de um outro discurso, paralelo ao primeiro, em que cada figura se encontrará chamada para uma outra atribuição que a da designação figurativa. Os conectores de isotopias entre os dois níveis de significação conduzem explicitamente o leitor sobre esta via interpretativa: "ouvia-a, apenas, pedir passagem, com ligeiros apitos apressados, como uma pessoa que a impaciência domina", conferindo-lhe assim um estatuto antropomorfo.

Mas esta própria personificação pontual está sob a dependência de outro deslocamento semântico de maior envergadura: a figura do "acoplamento" é o indicador, superficial, das operações de transformação que definem mais profundamente a sintaxe narrativa. Eis aqui três máquinas, que ocupam cada uma delas uma das três subseqüências do texto; a primeira tem "três rodas unidas duas a duas", a segunda tem "duas grandes rodas devoradoras", quanto à terceira, ela fica invisível, mesmo sob os sinais "em profusão" de sua aparição. Esta série de conexões, desconexões e acoplamentos deixa legível a ossatura narrativa do texto. A micro-narrativa das máquinas se torna assim emblemática da narrativa global: as locomotivas projetam como metáforas de estrutura as duas figuras femininas centrais de La 


\begin{tabular}{|l|l|l|l|l|l|l|}
\hline InterteXto & Uberaba & UFTM & $\begin{array}{l}\text { v. 1 } \\
\text { n. } 2\end{array}$ & p. 147-166 & 2008 - jul. / dez. & ISSN 1981-0601 \\
\hline
\end{tabular}

Bête humaine, Flore, a solitária, e Séverine, a impaciente. Suas duas fumaças se entremeiam durante a crise, a fumaça branca e a fumaça negra. Então, o desenho desaparece, as linhas ficam "transbordadas" pela abundância que transforma a ordem do visível, instalando formas confusas e discordantes, mascarando todas as conexões em sua ilusão sensível, antes que se produza enfim o "rompimento" que instaura novamente a toponímia, a linha e o cruzamento, ou seja, a racionalidade perceptiva inicial.

Estas poucas observações sugerem que a escrita zolaniana obedece a um verdadeiro sistema de esquematização discursiva da percepção: esta estaria no início de um processo cognitivo suscetível de fazer surgir, no momento de uma descrição, a totalidade significante do romance. Este "poderio de reflexibilidade" das figuras (Deleuze), cujo conteúdo repercute temas que as transbordam até a saturação, pede uma reflexão que diz respeito mais geralmente à narratividade figurativa. Se a percepção se traduz em modo de conhecimento, é porque ela responde a um esquema canônico mais ou menos fixo no uso do qual deveria ser possível relatar as seqüências essenciais.

A primeira etapa corresponderia assim a um / fazer saber / que instala a competência modal de um observador e manifestada por meio de predicados perceptivos. Dispondo uma certa ordem da visibilidade, ela prepara o desenvolvimento interpretativo. A segunda etapa é a da transformação, que assegura a conversão das figuras e dos percursos figurativos em percursos temáticos mais abstratos, a figura não mais designa somente seu objeto, ela se torna testemunha e agente: ela está pronta a entrar em outros programas que aqueles para os quais ela estava inicialmente destinada. Os conectores tais como a comparação ou a metáfora marcam muito esta operação na sua interface semântica. A terceira etapa, enfim, é a de um reconhecimento do "símbolo". O universo figurativo, doravante conduzido à abstração, é outro, embora permaneça o mesmo; ele garante nas marcas concretas do visível uma certa ordem finalizada do conhecimento. 


\begin{tabular}{|l|l|l|l|l|l|l|}
\hline InterteXto & Uberaba & UFTM & $\begin{array}{l}\text { v. 1 } \\
\text { n. } 2\end{array}$ & p. 147-166 & 2008 - jul. / dez. & ISSN 1981-0601 \\
\hline
\end{tabular}

\section{A aventura da percepção}

Do mesmo modo que a filosofia positivista tinha achado em Zola seu contista, a fenomenologia da percepção encontrou em Claude Simon um narrador: aquele que relata a aventura de perceber. Merleau-Ponty observava assim, em 1960, após a leitura de La route de Flandres: "Ver é a permissão de não pensar a coisa já que a vemos", e mais ainda: "Visão sensorial é visão de visionário"11. Ao alargamento zolaniano opõe-se aqui, em Simon, uma retratação do gesto perceptivo sobre si mesmo. A visão, voltada para o aprofundamento de sua qualidade sensorial, parece recuar em direção à sua forma elementar, primitiva e matricial: a tatilidade. O esquema figurativo seria então muitíssimo diferente daquele que acreditamos esclarecer precedentemente: nós reteremos dele, separadamente, dois caracteres que dizem respeito ao estatuto do sujeito e à escrita da percepção.

Se consideramos a proposição principal, no centro da passagem citada: "a locomotiva penetrou", constatamos que ela está literalmente inserida nas determinações que a precedem (o acúmulo dos particípios presentes) e nas que a sucedem até o final do texto. Sua função regente está enfraquecida pela sua posição. E seu sujeito "locomotiva" aparece no meio das sedimentações qualificativas como uma denominação inevitável no processo de uma construção: o termo concludente de uma rede de percepções da qual ele é a condensação lexical. De sorte que sua figura semântica se impõe de modo mais frágil do que todas aquelas que concorreram para construí-la. Do mesmo modo, a "multidão" não é o lugar de investida terminal das apreensões, das repulsões, de toda a massa tímica da defesa e do temor que constituem a forma neste instante. A mesma coisa ainda para os predicados cognitivos: não somente eles se apresentam no modo alético secundário do possível ou do provável ("sem dúvida prevendo este dia"), não somente eles estão imersos

\footnotetext{
11 "Cinq notes sur Claude Simon", in Esprit, 66, op. cit., p. 64-66.
} 


\begin{tabular}{|l|l|l|l|l|l|l|}
\hline InterteXto & Uberaba & UFTM & $\begin{array}{l}\text { v. } 1 \\
\text { n. } 2\end{array}$ & p. 147-166 & 2008 - jul. / dez. & ISSN 1981-0601 \\
\hline
\end{tabular}

num contexto emocional e sensível - e semanticamente inervados por ele mas também não remetem a nenhuma fonte subjetiva definível. Pode-se então dizer que a escrita de Simon retarda o sujeito: ela explora todo o espaço intermediário do que o faz surgir, sobre as dimensões tímica, perceptiva e cognitiva, e parece manter-se dentro desta mediação. Ela expõe a sensorialidade móvel que insere o sujeito no mundo dos objetos, mas suspende até ao limite o momento de nomeá-lo: isto é de fixá-lo. Então, como é o caso para a locomotiva a formação sensível está a tal ponto realizada que o substantivo, quando enfim aparece, ele tem a função de uma simples caixa de registro: sua significação não comanda mais nada, ele é apenas a síntese ressonante do processo que o formou, ele é o produto de uma definição "oblíqua" que tem toda a prioridade sobre ele. De um modo mais geral e, podemos dizer que, na escrita de Simon, o actante está enfraquecido. Sujeito e objeto, da enunciação como do enunciado, ele está colocado, sempre instável, no termo de uma rede complexa de relações predicativas que contribuíram juntas para constituí-lo. Ao contrário do sujeito zolaniano, sentinela que controla a ordem da visão, este está mergulhado, por uma espécie de dissipação dócil e aquiescente, no próprio "meio" da percepção, como que para favorecer a explicitação do que o institui, na solidariedade estreita, íntima, do vidente e do visível.

Na realidade, é o percurso narrativo da percepção (narrativo, no sentido elementar de relação de junção entre sujeito e objeto) que é visado na "descrição": um percurso de diferenciação actancial. Merleau-Ponty destaca freqüentemente o paradoxo da percepção12: dissipando-se na "textura" da visão, no "entrelaçamento", na "intersecção", no "avanço", na "imanência" do percebido e daquele que percebe, no "sepultamento" do sujeito que vê no seio dos objetos visíveis, ele procura assiduamente o limiar, o corte originário e necessário que instaura nossas percepções como possibilidades do

12 Cf. especificamente Le visible et l'invisible, Paris, Gallimard, 1964; e Le primat de la perception et ses conséquences philosophiques, Grenoble, Cynara, 1989. 


\begin{tabular}{|l|l|l|l|l|l|l|}
\hline InterteXto & Uberaba & UFTM & $\begin{array}{l}\text { v. 1 } \\
\text { n. } 2\end{array}$ & p. 147-166 & 2008 - jul. / dez. & ISSN 1981-0601 \\
\hline
\end{tabular}

conhecimento. Ele procura isolar a ruptura a partir da qual se organizam as práticas do saber. Este intervalo entre o olhar e a coisa é ocupado por uma estrutura modal: o /crer/, a "crença perceptiva". É ela quem fundamenta a distinção, e a impossível indistinção, entre objetos vistos e sujeitos que vêem. Fora deste /crer/ fundador, a imersão seria total, dispersa, na inerência absoluta de um sujeito e de um objeto que seriam a partir de então inomináveis. É bem este limiar, o limiar da actancialização, que visa, no nosso ponto de vista, o texto de Claude Simon, levando-se aos limites da indizibilidade do visível e dando "a palavra" ao imperceptível da percepção. Isto explica, a menos que seja o efeito produzido, a forma de uma escrita que procede de uma apreensão tensa, difícil, por aproximações graduais, sedimentações e avanços. São as superposições quase sinonímicas: "por uma espécie de instintivo horror, de intuitivo instinto de repulsa", ou ainda a diferenciação progressiva entre dois medos, o temor, virtualizado, de "escorregar sob as rodas", e o horror, atualizado, de penetrar dentro dos vagões. É a evolução do modo sensorial, quando da iminente subida para dentro do trem, que substitui na ordem do visível ("fosso", "cânion") a ordem mais elementar do táctil ("invisível muralha", "invisível barreira") e inverte na abolição da distância a relação entre o sujeito e o objeto da percepção: é o trem que avança dentro da multidão, é o vagão que vai incorporá-la; a correspondência das figuras visuais e táteis com as que qualificavam a locomotiva no início do texto: "aérea e monumental", reforça o escondimento do sujeito dentro de sua percepção, o "tornar-se trem" da multidão.

Assim a "diferença" na escrita de Claude Simon antes de ser categórica, é sempre uma diferença de intensidade; em Zola, articulada em junções, ela era essencialmente categorial. $O$ espaço se apresentava como uma complexidade descontínua e segmentável, ele se apresenta como um conjunto nebuloso, submetido a variações de tensão sensorial. O sujeito, difuso nas figuras de sua percepção, está enfraquecido e incerto; ele formava o pedestal 


\begin{tabular}{|l|l|l|l|l|l|l|}
\hline InterteXto & Uberaba & UFTM & $\begin{array}{l}\text { v. 1 } \\
\text { n. } 2\end{array}$ & p. 147-166 & 2008 - jul. / dez. & ISSN 1981-0601 \\
\hline
\end{tabular}

inamovível da construção figurativa, garantia da visão e responsável pela extensão aplicativa das categorias espaciais.

\section{O trem da justiça}

A distinção, para além da dimensão estilística, implica então regimes diferentes de figuratividade. Ela nos permitiu explicitar, de maneira contrastiva, algumas características do discurso espacial no romance de Zola, que são por outro lado admiravelmente recorrentes. De fato a descrição da mesma estação, com suas idas e vindas de trens sobre os trilhos, é retomada cinco vezes no primeiro capítulo de La Bête humaine, e rearticula em cada circunstância o mesmo esquematismo espacial. Este, sustentando o nível figurativo superficial, mas formulado nos termos mais abstratos de uma figuratividade profunda, autoriza a hipótese de uma espacialidade que, desligada da ordem sensorial, regeria como significante a dimensão cognitiva do discurso no romance.

Este esquema espacial abstrato pode facilmente ser reduzido ao enunciado de duas categorias fundamentais da sintaxe narrativa: a junção e a suspensão da junção. À primeira categoria, que se subdivide em relações de conjunção e de disjunção, correspondem as figuras do acoplamento, da ligação, da ramificação, das conexões e das desconexões, do engate e desengate das máquinas. Os percursos que ela determina são os da sintaxe elementar da narratividade. À segunda correspondem as figuras dissolventes que confundem as categorias, ocultam o desenho, apagam as linhas e os contornos: o vapor, a fumaça, a bruma, a mata espessa ou a obscuridade tornam então desarmônicas e indecisas as formas segmentadas da sintaxe inicial; a nuvem deforma os objetos e seus percursos, eles se tornam difusos e indiscerníveis.

Porém, esta transformação da qual se percebe claramente o núcleo sintáxico (estado de junção depois negação ou interrupção deste estado) encontra-se novamente em outros lugares do romance, onde ela organiza, 


\begin{tabular}{|l|l|l|l|l|l|l|}
\hline InterteXto & Uberaba & UFTM & $\begin{array}{l}\text { v. } 1 \\
\text { n. } 2\end{array}$ & p. 147-166 & 2008 - jul. / dez. & ISSN 1981-0601 \\
\hline
\end{tabular}

enquanto significante, outros conteúdos além do espaço visual disposto nas seqüências descritivas. Ela comanda, por exemplo, o discurso explicativo da patologia que afeta Jacques Lantier. A "ruptura" repousa para começar sobre um jogo alternativo de disjunções e de conjunções no seio de um sujeito cindido em dois actantes: ele está "ausente de seu ser" (p. 1212), "aterrorizado de não ser mais ele", é necessário que ele "vá em frente, mais longe, sempre mais longe, para evitar o outro" (p. 1227); e depois de repente, conjunção, ele é "surpreendido voltando bruscamente em posse de si mesmo" (p. 1213). Estas transladações acabam por se misturarem numa "fumaça" dissipativa das próprias categorias actanciais, por meio de figuras espaciais, notemo-lo: "eram dentro de seu ser súbitas perdas de equilíbrio como rupturas, cavidades pelas quais seu eu escapava-lhe, no meio de uma espécie de densa fumaça que deformava tudo" (p. 1043).

O modelo desta transformação espacial "profunda" determina também, e isso é mais importante com relação à organização geral do romance, o funcionamento do discurso de veridicidade da justiça: conjunção dos percursos disjuntos que constrói, por meio de "mecanismos complicados", uma certeza "deslumbrante", e dissolução final desta certeza categórica logo que "o vôo silencioso da melancólica verdade" atravessa um instante a sala onde ocorre o processo. O percurso cognitivo do juiz Denizet, simétrico na sua disposição romanesca do percurso figurativo dos trens (um no fim, o outro no início), é reconstruído como uma série de ligações, redes, ramificações, conjunções aparentemente indestrutíveis, isto é incontestáveis. Seu sucesso é de ter sabido "desenterrar o velho processo judicial e religá-lo ao novo crime", de ter conduzido "o duplo processo em um único bloco" (p. 1314), de ter dado "à sua estrutura de acusação uma solidez [...] indestrutível", um "poder de evidência" (p. 1311). Seu "edifício de lógica" estava tão bem edificado que "se movimentássemos uma única peça, tudo ruiria" (p. 1318). Mas, de conformidade com o esquema espacial, o sistema categórico da construção judiciária se baseia no indiscernível que representa aqui a "mata espessa": "A 


\begin{tabular}{|l|l|l|l|l|l|l|}
\hline InterteXto & Uberaba & UFTM & $\begin{array}{l}\text { v. 1 } \\
\text { n. } 2\end{array}$ & p. 147-166 & 2008 - jul. / dez. & ISSN 1981-0601 \\
\hline
\end{tabular}

justiça, qual ilusão última! Querer ser justo não é um engodo, quando a verdade é tão obstruída de mata espessa?" (p. 1316). A bela junção de veridicidade se dissipa igualmente no espaço furtivo e móvel da emoção que propaga um instante de verdade contra a "mentira lógica": "uma emoção vinda, eles não sabiam de onde, apertou na garganta por um instante: era a verdade que passava muda" (p. 1322).

Uma análise mais sistemática da espacialidade no seio do discurso cognitivo da instrução e do processo judicial confirmaria, no nosso ponto de vista, a existência deste esquema espacial abstrato que comanda o desenvolvimento. Ela mostraria, como tentamos sugeri-lo por algumas observações, que o nível figurativo profundo, resultante de uma concepção "cognitivista" da percepção, determina em uma única peça e através da mesma estruturação o discurso figurativo do tráfego ferroviário e o discurso interpretativo da elaboração do saber "verdadeiro". Esta correlação estrutural faz justiça, parece-nos, à "intenção" de Zola quando, procurando justificar a unidade das duas narrativas, ferroviária e judiciária, ele observava que the "seria necessário preservar o grande tráfego de uma linha como ação de apoio contínuo" (nós destacamos). No fundo, ela não faz mais do que explicitar as razões internas: pois esta ação de apoio é a de um mesmo regime de espacialização que regula o desenvolvimento dos dois discursos e os homogeneíza numa mesma escrita. A rede das metáforas espaciais manifesta, na superfície, os princípios desta organização e reduz a eficácia simbólica delas. O espaço figurativo profundo assegura a "junção" entre o desdobramento do conhecimento sensível e o do conhecimento inteligível; cada um deles acha no outro, graças ao espaço figurativo, sua motivação e seu referente interno: a ilusão figurativa e a ilusão interpretativa se juntam através dele. Esse devaneio da espacialidade, tão pregnante em La Bête humaine quanto em Germinal, poderia conduzir de forma mais geral a um refinamento do conceito de figuratividade e ao estudo do que especifica estas 


\begin{tabular}{|l|l|l|l|l|l|l|}
\hline InterteXto & Uberaba & UFTM & v. 1 & p. 147-166 & 2008 - jul. / dez. & ISSN 1981-0601 \\
n. 2 & & &
\end{tabular}

movimentações da visão na literatura. Seja como for, o trem e a justiça estão aqui nos mesmos trilhos. 